\title{
Circulating Endothelial Progenitor Cells in Women with Coronary Microvascular Dysfunction: A Pilot Study
}

Case Report

Phancao A ${ }^{1}$, Mehta PK ${ }^{1}$, Dhawan $\mathrm{S}^{1}$, Cook-Wiens $\mathrm{G}^{2}$, Shufelt $\mathrm{C}^{1}$, Chowdhury $\mathrm{S}^{1}$, Taylor $\mathrm{D}^{3}$, Zierold $\mathrm{C}^{4}$, Minissian $\mathrm{M}^{1}$, Bairey Merz $\mathrm{CN}^{1 *}$

${ }^{1}$ Barbra Streis and Women's Heart Center, Cedars Sinai Heart Institute, LA, USA.

${ }^{2}$ Biostatistics and Bioinformatics Core, Cedars Sinai Medical Center, Los Angeles, CA, USA.

${ }^{3}$ Texas Heart Institute, Houston, TX, USA.

${ }^{4}$ Mayo Clinic, Rochester, MN, USA.

\section{Abstract}

Background: Endothelial progenitor cells (EPCs) are a diverse population of mononuclear cells derived from bone marrow that are mobilized in response to vascular injury, circulate in peripheral blood and contribute to vascular repair. We evaluated circulating EPCs in women with coronary microvascular dysfunction (CMD) compared to matched controls. Methods: Twenty-nine symptomatic women with no obstructive coronary atherosclerosis $(<50 \%$ epicardial coronary stenosis), and diagnosed with CMD invasively, and eleven reference control women were included. EPCs were defined as cells either expressing cell surface markers CD34+/CD133+ or CD34+/VEGFR2+.

Results: Mean and median levels of CD34+/CD133+ and CD34+/VEGFR2+ in the CMD group trended lower than the reference control group, although this was not statistically significant. There was a significant positive correlation between CD34+/CD133+ subsets and LDL levels which was not found with CD34+/VEGFR2+.

Conclusions: These pilot data in women with CMD demonstrate no difference in EPCs between CMD women compared to reference control subjects. Our study combined with prior publications in similarly characterized and larger populations suggests that absolute EPC levels (BMDAC), but not EPCs alone, may be adequately sensitive for providing a complete depiction of endothelial injury or function in this population.

\section{Introduction}

Endothelial progenitor cells (EPCs) are a diverse population of mononuclear cells derived from bone marrow that are mobilized in response to vascular injury [1,2], and circulate in peripheral blood and contribute to vascular repair [3, 4]. Subpopulations of circulating EPCs expressing cell surface makers CD34+, CD133+, or vascular endothelial growth factor receptor (VEGFR) $2+$ have been linked with coronary vascular dysfunction [5-11]. In addition, reduced circulating EPC levels are associated with cardiovascular events [11] and acceleration of atherosclerosis [8].

Women with chest pain, evidence of ischemia, and no obstructive coronary artery disease (CAD) often have coronary microvascular dysfunction (CMD) $[12,13]$. CMD is related to both endothelial dependent and non-endothelial dependent mechanisms, and associated with adverse cardiovascular outcomes [12]. Invasive coronary reactivity testing (CRT) can be used to diagnose CMD [14]. We evaluated circulating EPCs in women with CMD compared to age and BMI matched controls, and studied relationships between CD34+/VEGFR2+ and CD34+/CD133+ subsets of EPCs and measures of CRT.

\section{Methods}

\section{Study Subjects}

Twenty-nine symptomatic women with no obstructive coronary atherosclerosis ( $<50 \%$ epicardial coronary stenosis), and diagnosed with CMD by CRT, and eleven reference control women were included after providing informed consent. The reference control subjects were age and BMI-matched asymptomatic wom-

*Corresponding Author

C. Noel Bairey Merz, MD,

Barbra Streis and Women's Heart Center, Cedars Sinai Heart Institute, 127 S San Vicente Blvd A3206, Los Angeles, California 90048, USA.

Tel: (310) 423-9680

Fax: (310) 423-9681

Email: merz@cshs.org

Received: October 06, 2016

Accepted: November 07, 2016

Published: November 08, 2016

Citation: Phancao A, Mehta PK, Dhawan S, Cook-Wiens G, Bairey Merz CN, et al., (2016) Circulating Endothelial Progenitor Cells in Women with Coronary Microvascular Dysfunction: A Pilot Study. Int J Stem Cell Res Transplant. 4(9), 256-259. doi: http://dx.doi.org/10.19070/2328-3548-1600039

Copyright: Bairey Merz CN ${ }^{\circ}$ 2016. This is an open-access article distributed under the terms of the Creative Commons Attribution License, which permits unrestricted use, distribution and reproduction in any medium, provided the original author and source are credited. 
en with no cardiac risk factors, not on any cardiac medications, and who had a normal exercise stress test using the Bruce protocol.

All women in the CMD group had undergone clinically indicated CRT for evaluation of endothelial- or non-endothelial-dependent vascular function abnormality using intracoronary adenosine, acetylcholine, and nitroglycerin, as previously published [12, 14]. CMD was defined as those with at least one abnormality in CRT in either endothelial- or non-endothelial-dependent pathways [14, 15].

\section{Assessment of EPCs by Fluorescence Activated Cell Sorting}

A 10-15 ml sample of venous blood was used for isolation of EPCs. Samples were processed within 4 hours after collection. Peripheral blood mononuclear cells (MNCs) were isolated using Ficoll density gradient centrifugation (Ficoll-Paque, Amersham), and washed twice with phosphate buffered saline. MNCs were stained for fluorescence activated cell sorting analysis using the following monoclonal antibodies: FITC-conjugated anti-human CD34 mAb (Becton Dickinson), PE-conjugated anti-human CD133 mAb (Miltenyi Biotech, Germany), and PE-labeled VEGF R2-Receptor (Kinase Domain Receptor [KDR], R\&D Systems). Staining was performed immediately after isolation of MNCs. EPCs were defined as cells either expressing cell surface markers CD34+/CD133+ or CD34+/VEGFR2+. Fluorescence activated cell sorting results were represented as "number of events" per 50,000, and EPCs were expressed as absolute percentage of cells per total number of cytometric events.

\section{Statistical Analysis}

All statistical analysis was performed using SAS (ver. 9.3; The SAS Institute, Cary, NC). Summary data are expressed as means, medians, and standard deviation for continuous variables and frequencies (\%) for categorical ones. Pearson correlation coefficients were used to find associations between EPCs and clinical and CRT data. Kruskal-Wallis tests were used to compare EPCs between groups due to skewed distributions. A p-value of less than 0.05 was considered to indicate statistical significance.

\section{Results}

Baseline characteristics of women with CMD and reference control subjects are summarized in Table 1. By design, the reference control group did not have any cardiovascular risk factors. Three reference controls took self-prescribed aspirin. A majority of the CMD group were taking a statin, $28 \%$ were on beta blockers and nitrates, while a minority were taking angiotensin converting enzyme inhibitors.

Among CMD group, mean invasive CRT measures demonstrated the following: mean coronary flow reserve to adenosine was 2.5 \pm 0.5 ; mean change in coronary artery diameter to Ach was $15 \pm$ $23 \%$; mean change in coronary blood flow to Ach was $49 \pm 80 \%$; and mean change in coronary artery diameter to nitroglycerin was $12 \pm 16 \%$.

EPC levels obtained from fluorescence activated cell sorting are summarized in Table 2. Mean and median levels of CD34+/ CD133+ and CD34+/VEGFR2+ in the CMD group trended lower than the reference control group, although this was not statistically significant.

Both subsets of EPCs, CD34+/CD133+ and CD34+/VEGFR2+ did not significantly correlate with any measures of CRT. Furthermore, EPCs did not correlate with BMI, systolic or diastolic blood pressure, or resting heart rate. There was a significant positive correlation between CD34+/CD133+ subsets and LDL

Table 1. Demographics and Clinical Variables.

\begin{tabular}{|c|c|c|}
\hline & $\begin{array}{c}\text { CMD } \\
(n=29)\end{array}$ & $\begin{array}{l}\text { Reference Controls } \\
\qquad(\mathrm{n}=11)\end{array}$ \\
\hline Age $\pm \mathrm{SD}$ (yrs) & $53 \pm 12$ & $53 \pm 6$ \\
\hline Body Mass Index \pm SD & $26.8 \pm 5.4$ & $26.4 \pm 3.2$ \\
\hline Rest Heart Rate \pm SD (bpm) & $64 \pm 11$ & $63 \pm 6$ \\
\hline Systolic Blood Pressure \pm SD $(\mathrm{mmHg})$ & $143 \pm 26$ & $132 \pm 25$ \\
\hline Diastolic Blood Pressure $\pm \mathrm{SD}(\mathrm{mmHg})$ & $70 \pm 14$ & $61 \pm 11$ \\
\hline Hyperlipidemia (\%) & $11(38)$ & 0 \\
\hline Hypertension $(\%)$ & $10(34)$ & 0 \\
\hline Family history of premature CAD (\%) & $16(55)$ & 0 \\
\hline Tobacco use $(\%)$ & $7(24)$ & 0 \\
\hline Diabetes mellitus (\%) & $3(10)$ & 0 \\
\hline Aspirin $(\%)$ & $17(59)$ & $3(27)$ \\
\hline Statins $(\%)$ & $21(72)$ & 0 \\
\hline Beta blockers $(\%)$ & $8(28)$ & 0 \\
\hline Calcium channel antagonists (\%) & $3(10)$ & 0 \\
\hline ACE inhibitors $(\%)$ & $2(7)$ & 0 \\
\hline Nitrates $(\%)$ & $8(28)$ & 0 \\
\hline
\end{tabular}


Table 2. Levels of Endothelial Progenitor Cells.

\begin{tabular}{|c|c|c|c|}
\hline & $\begin{array}{c}\text { CMD } \\
\mathbf{n}=\mathbf{2 6}(\mathbf{m e a n} \mathbf{\pm} \mathbf{~ S D})\end{array}$ & $\begin{array}{c}\text { Reference Controls } \mathbf{n = 9} \\
(\mathbf{m e a n} \mathbf{\mathbf { S D }})\end{array}$ & p-Value \\
\hline CD34+, VEGFR2+ $(\%)$ & $0.18 \pm 0.33$ & $0.21 \pm 0.23$ & 0.35 \\
\hline CD34+, CD133+ $(\%)$ & $0.04 \pm 0.03$ & $0.09 \pm 0.10$ & 0.17 \\
\hline CD34+ $(\%)$ & $0.08 \pm 0.07$ & $0.12 \pm 0.12$ & 0.14 \\
\hline
\end{tabular}

Table 3. Correlations Between EPCs and Clinical Variables.

\begin{tabular}{|c|c|c|}
\hline \multicolumn{3}{|c|}{$\begin{array}{c}\text { Correlation Coefficients (r) } \\
\text { p-value }\end{array}$} \\
\hline \multirow{2}{*}{ BMI } & CD34 + VEGFR2 + & CD34 + CD133 + \\
& 0.11 & -0.01 \\
\multirow{2}{*}{ Rest SBP } & -0.51 & 0.96 \\
\hline \multirow{2}{*}{ Rest DBP } & 0.94 & 0.08 \\
& -0.09 & 0.66 \\
\hline \multirow{2}{*}{ Rest HR } & 0.67 & -0.20 \\
& 0.16 & 0.32 \\
\hline \multirow{2}{*}{ LDL } & 0.36 & 0.17 \\
& -0.05 & 0.34 \\
\hline
\end{tabular}

levels which was not found with CD34+/VEGFR2+ (Table 3).

\section{Discussion}

Our pilot study shows no significant differences in levels of circulating EPCs determined by flow cytometry in women with CMD compared to controls, although there was a trend toward lower levels in the CMD group. No correlation was demonstrated between levels of EPC subpopulations CD34+/VEGFR2+ or CD34+/CD133+ and CRT measures for non-endothelial and endothelial function. We also did not find a correlation between BMI, baseline heart rate and blood pressure with EPCs, while LDL correlated positively with CD34+/CD133+ subset.

In a previously published paper in 32 CMD women from the Women's Ischemia Syndrome Evaluation (WISE) cohort, the number of circulating endothelial cells were similarly not different compared to healthy reference group $[35(10,320)$ vs. $30(20,48)$; $\mathrm{p}=0.53$ ], and circulating endothelial cells did not relate to CFR, however bone-marrow derived angiogenic cell (BMDAC) function and number of colonies were lower in CMD women [16]. The variability between the prior and current results is likely due to differences in the EPC measure methods, whereby BMDAC may be a more sensitive biomarker for CMD.

Small sample size studies that are not phenotyped for CMD (and categorized as cardiac sydrome $\mathrm{X}$ ) have demonstrated mixed results regarding EPC levels $[10,17]$. In a study of 57 subjects, Boilson et al., found that those with coronary endothelial dysfunction had lower levels of circulating CD34+/CD45dim and CD34+/ CD45dim/CD133+ EPCs when compared to those without endothelial dysfunction [18]. This variability regarding EPC data in the literature may be related to variability in the methods of EPC collection and isolation, and differences in the definition of EPCs. Levels of EPCs appear to be dynamic in response to severity of disease states as well as acute ischemia [19-21]. Severity of obstructive CAD affects levels of circulating EPCs with those having multivessel CAD having lower levels of EPCs compared to those having single vessel obstructive CAD [22]. Recently Chan et al., reported that EPCs differ in their associations with obstructive CAD severity, where early EPCs do not correlate with CAD severity, but late outgrowth endothelial cells correlate with CAD severity [23]. We hypothesize that the levels of EPCs in women with CMD may also be variable related to the presence and extent of non-obstructive CAD.

It should be noted that in this study, $72 \%$ of women with CMD were treated with statins at the time of EPC collection, and statins have been shown to increase mobilization and proliferation of EPCs in cardiac patients [24-26]. We found that LDL levels correlated positively with CD34/CD133+, but not CD34+/VEGFR2+ cells. The significance of this is uncertain because $72 \%$ of our CMD group was on statins and mean LDL was $100 \pm 36$. Wang et al., [27] described that ox-LDL is associated with decreased levels of EPCs, in contrast to our positive correlation in our subjects receiving statins.

\section{Limitations}

We conducted a small pilot study of well-phenotyped women with $\mathrm{CMD}$, therefore our results may not be relevant to women with other forms of cardiovascular disease as well as men. EPC counts may fluctuate related to menstrual cycle which was not evaluated in this pilot study. Although, absolute levels of EPCs do not correlated with degree of endothelial dysfunction as measured by CRT, we did not assess functional properties of EPCs in this study. 


\section{Conclusion}

In conclusion, these pilot data in women with CMD demonstrate no difference in EPCs between CMD women compared to reference control subjects. Our study combined with prior publications in similarly characterized and larger populations suggests that absolute EPC levels (BMDAC), but not EPCs alone, may be adequately sensitive for providing a complete depiction of endothelial injury or function in this population.

\section{References}

[1]. Leone AM, Rutella S, Bonanno G, Abbate A, Crea F, et al., (2005) Mobilization of bone marrow-derived stem cells after myocardial infarction and left ventricular function. Eur Heart J. 26(12): 1196-1204.

[2]. Porto I, Leone AM, De Maria GL, Niccoli G, Crea F, et al., (2011) Are endothelial progenitor cells mobilized by myocardial ischemia or myocardial necrosis? A cardiac magnetic resonance study. Atherosclerosis. 216(2): 355-358.

[3]. Asahara T, Murohara T, Sullivan A, Isner JM, Silver M, et al., (1997) Isolation of putative progenitor endothelial cells for angiogenesis. Science. 275(5302): 964-967.

[4]. Hur J, Yoon CH, Kim HS, Lee MM, Park YB, et al., (2004) Characterization of two types of endothelial progenitor cells and their different contributions to neovasculogenesis. Arterioscler Thromb Vasc Biol. 24(2): 288-293.

[5]. Kalka C, Tehrani H, Laudenberg B, Vale PR, Asahara T, et al., (2001) VEGF gene transfer mobilizes endothelial progenitor cells in patients with inoperable coronary disease. Ann Thorac Surg. 70(3): 829-834.

[6]. Kawamoto A, Gwon HC, Iwaguro H, Uchida S, Silver M, et al., (2001) Therapeutic potential of ex vivo expanded endothelial progenitor cells for myocardial ischemia. Circulation. 103(5): 634-637.

[7]. Kocher AA, Schuster MD, Szabolcs MJ,Takuma S, Wang J, et al., (2001) Neovascularization of ischemic myocardium by human bone-marrow-derived angioblasts prevents cardiomyocyte apoptosis, reduces remodeling and improves cardiac function. Nat Med. 7(4): 430-436.

[8]. Schmidt-Lucke C, Rossig L, Fichtlscherer S, Vasa M, Kamper U, et al., (2005) Reduced number of circulating endothelial progenitor cells predicts future cardiovascular events: proof of concept for the clinical importance of endogenous vascular repair. Circulation. 111(22): 2981-2987.

[9]. Shintani S, Murohara T, Ikeda H, Katoh A, Oike Y, et al., (2001) Mobilization of endothelial progenitor cells in patients with acute myocardial infarction. Circulation. 103(23): 2776-2779.

[10]. Shmilovich H, Deutsch V, Roth A, Miller H, Keren G, et al., (2007) Circulating endothelial progenitor cells in patients with cardiac syndrome $\mathrm{X}$. Heart. 93(9): 1071-1076.

[11]. Werner N, Kosiol S, Schiegl T, Link A, Bohm M, et al., (2005) Circulating endothelial progenitor cells and cardiovascular outcomes. N Engl J Med. 353(10): 999-1007.

[12]. Pepine CJ, Anderson RD, Sharaf BL, Reis SE, Sopko G, et al., (2010) Coronary microvascular reactivity to adenosine predicts adverse outcome in women evaluated for suspected ischemia results from the National Heart, Lung and Blood Institute WISE (Women's Ischemia Syndrome Evaluation) study. J Am Coll Cardiol. 55(25): 2825-2832.

[13]. Reis SE, Holubkov R, Conrad Smith AJ, Kelsey SF, Merz CN, et al., (2001)
Coronary microvascular dysfunction is highly prevalent in women with chest pain in the absence of coronary artery disease: results from the NHLBI WISE study. Am Heart J. 141(5): 735-741.

[14]. Wei J, Mehta PK, Johnson BD, Shaw L, Merz CN, et al., (2012) Safety of coronary reactivity testing in women with no obstructive coronary artery disease: results from the NHLBI-sponsored WISE (Women's Ischemia Syndrome Evaluation) study. JACC Cardiovascular interventions. 5(6): 646653.

[15]. Thomson LE, Wei J, Agarwal M, Mehta PK, Pepine CJ, et al., (2015) Cardiac magnetic resonance myocardial perfusion reserve index is reduced in women with coronary microvascular dysfunction. A National Heart, Lung, and Blood Institute-sponsored study from the Women's Ischemia Syndrome Evaluation. Circulation Cardiovascular imaging. 8(4): 2481.

[16]. Mohandas R, Sautina L, Li S, Wen X, Huo T, et al., (2013) Number and function of bone-marrow derived angiogenic cells and coronary flow reserve in women without obstructive coronary artery disease: a substudy of the NHLBI-sponsored Women's Ischemia Syndrome Evaluation (WISE). PloS one. 8(12): e81595.

[17]. Huang PH, Chen YH, Chen YL, Wu TC, Chen JW, et al., (2007) Vascular endothelial function and circulating endothelial progenitor cells in patients with cardiac syndrome X. Heart. 93(9): 1064-1070.

[18]. Boilson BA, Kiernan TJ, Harbuzariu A, Nelson RE, Lerman A, et al., (2008) Circulating CD34+ cell subsets in patients with coronary endothelial dysfunction. 5(8): 489-496.

[19]. George J, Goldstein E, Abashidze S, Deutsch V, Herz I,et al., (2004) Circulating endothelial progenitor cells in patients with unstable angina: association with systemic inflammation. Eur Heart J. 25(12): 1003-1008.

[20]. Massa M, Rosti V, Ferrario M, Rosso R, Pecci A, et al., (2005) Increased circulating hematopoietic and endothelial progenitor cells in the early phase of acute myocardial infarction. Blood. 105(1): 199-206.

[21]. Adams V, Lenk K, Linke A, Erbs S, Lenz D, et al., (2004) Increase of circulating endothelial progenitor cells in patients with coronary artery disease after exercise-induced ischemia. Arterioscler Thromb Vasc Biol. 24(4): 684-690.

[22]. Chen MC, Chen CJ, Yang CH, Liu WH, Fang CY, et al., (2008) Relationship of the percentage of circulating endothelial progenitor cell to the severity of coronary artery disease. Heart Vessels. 23(1): 47-52.

[23]. Chan KH, Simpson PJ, Yong AS, Dunn LL, Yu Y, et al., (2014) The relationship between endothelial progenitor cell populations and epicardial and microvascular coronary disease-a cellular, angiographic and physiologic study. PloS one. 9(4): e93980.

[24]. Baran C, Durdu S, Dalva K, Zaim C, Doagan A, et al., (2012) Effects of preoperative short term use of atorvastatin on endothelial progenitor cells after coronary surgery: a randomized, controlled trial. Stem Cell Rev. 8(3): 963-971.

[25]. Hibbert B, Ma X, Pourdjabbar A, Simard T, Sun J, et al., (2011) Preprocedural atorvastatin mobilizes endothelial progenitor cells: clues to the salutary effects of statins on healing of stented human arteries. PloS one. 6(1): e16413.

[26]. Paradisi G, Bracaglia M, Basile F, Caruso A, De waure C, et al., (2012) Effect of pravastatin on endothelial function and endothelial progenitor cells in healthy postmenopausal women. Clin Exp Obstet Gynecol. 39(2): 153159.

[27]. Wang X, Chen J, Tao Q, Zhu J, Shang Y (2004) Effects of ox-LDL on number and activity of circulating endothelial progenitor cells. Drug and chemical toxicology. 27(3): 243-255. 